\title{
Engineering Poly(ethylene glycol) Particles for
}

\section{Improved Biodistribution}

Jiwei Cui, ${ }^{\dagger, \perp}$ Robert De Rose, ${ }^{\ddagger}, \perp$ Karen Alt, ${ }^{\S}$ Sheilajen Alcantara, ${ }^{\ddagger}$ Brett M. Paterson, ${ }^{\#}$ Kang Liang, ${ }^{\dagger}$ Ming Hu, ${ }^{\dagger}$ Joseph J. Richardson, $^{\dagger}$ Yan Yan, ${ }^{\dagger}$ Charmaine M. Jeffery, ${ }^{\Delta}$ Roger I. Price, ${ }^{\Delta}$ Karlheinz Peter, ${ }^{\S}$ Christoph E. Hagemeyer, ${ }^{\S}$ Paul S. Donnelly, ${ }^{\#}$ Stephen J. Kent, ${ }^{\ddagger} *$ and Frank Caruso $^{\dagger} *$

${ }^{\dagger}$ ARC Centre of Excellence in Convergent Bio-Nano Science and Technology, and the Department of Chemical and Biomolecular Engineering, The University of Melbourne, Parkville, Victoria 3010, Australia. ${ }^{\ddagger}$ ARC Centre of Excellence in Convergent Bio-Nano Science and Technology, and the Department of Microbiology and Immunology, The University of Melbourne, at the Peter Doherty Institute for Infection and Immunity, Parkville, Victoria 3010, Australia. ${ }^{\S}$ Vascular Biotechnology/Atherothrombosis and Vascular Biology, Baker IDI Heart and Diabetes Institute, Melbourne, Victoria 3004, Australia. "School of Chemistry and Bio21 Molecular Science and Biotechnology Institute, The University of Melbourne, Parkville, Victoria 3010, Australia. ${ }^{\Delta}$ Department of Medical Technology and Physics, Sir Charles Gairdner Hospital, Nedlands, Western Australia 6009, Australia; School of Physics, The University of Western Australia, Nedlands, Western Australia 6009, Australia.

KEYWORDS: nanoengineering, mesoporous silica particles, PEG, hydrogel particles, cell association, biodistribution 


\section{ABSTRACT}

We report the engineering of poly(ethylene glycol) (PEG) hydrogel particles using a mesoporous silica (MS) templating method via tuning PEG molecular weight, particle size and the presence or absence of the template, and investigate the cell association and biodistribution of these particles. An ex vivo assay based on whole human blood that is more sensitive and relevant in vitro assays than traditional cell-line based assays for predicting in vivo circulation behavior is introduced. The association of MS@PEG particles (template present) with granulocytes and monocytes is higher compared with neat PEG particles (template absent). Increasing the PEG molecular weight (from 10 to $40 \mathrm{kDa}$ ) or decreasing the particle size (from 1400 to $150 \mathrm{~nm}$ ) reduces phagocytic blood cell association of the PEG particles. Mice biodistribution studies show that the PEG particles exhibit extended circulation times (>12 h) compared with the MS@PEG particles and that the retention of smaller PEG particles $(150 \mathrm{~nm})$ in blood, when compared with larger PEG particles (>400 $\mathrm{nm})$, is increased at least four-fold at $12 \mathrm{~h}$ after injection. Our findings highlight the influence of unique aspects of polymer hydrogel particles on biological interactions. The reported PEG hydrogel particles represent a new class of polymer carriers with potential biomedical applications. 
The application of nanotechnology to drug delivery is widely expected to revolutionize the treatment of a range of diseases. ${ }^{1-5}$ In recent years, nanoengineered polymer hydrogel particles have received interest as drug delivery systems because they can be fabricated through versatile techniques that provide precise control over the particle physiochemical properties and functionality. ${ }^{6-8}$ Although important parameters have been investigated, such as the influence of particle size, shape, and elasticity on biological systems in vitro and in vivo, ${ }^{9-11}$ it remains a challenge to control and predict the ability to avoid clearance by phagocytic blood cells before reaching the desired site of action. Poly(ethylene glycol) (PEG), an FDA-approved polymer that enhances surface hydrophilicity, and reduces association and uptake by phagocytes, is the most frequently used so-called "stealth" material for this application. ${ }^{12-14}$ The stealth properties of PEGylated particles are usually dependent on the PEG chain architecture and PEG surface density, both of which are difficult to finely control and simulate. ${ }^{15-18}$ An alternative method to circumvent the issues relating to PEG chain architecture and PEG density is to use particles composed primarily of PEG.

Several approaches have been reported to generate PEG-based particles. DeSimone and coworkers recently developed a "PRINT" method for the preparation of PEG-based hydrogel particles with different shapes and sizes. ${ }^{19,20}$ The Doyle group reported micrometer-sized PEG-based particles with tunable size via a continuous-flow lithography method. ${ }^{21-23}$ In addition, we introduced a strategy to produce PEG-based hydrogel particles via click-driven chemistry or surface-initiated polymerization within template particles. ${ }^{24,25}$ These PEG-based particles were prepared via polymerization of PEG diacrylate and/or PEG monomethacrylate. Recently, we reported PEG particles solely composed of 8-arm-PEG with tunable elasticity via the mesoporous silica (MS) templating method, ${ }^{26}$ which has proven to be a versatile method in the fabrication of polymer particles for drug and gene delivery because it allows precise control over size, shape, chemical composition, and elasticity, as well as cargo 
loading and release. ${ }^{27-31}$ The deformability behavior of these particles in microchannels can be tailored to be similar to that of red blood cells (RBCs). While the reported approaches have shown their versatility to fabricate PEG particles on-demand, their detailed biological interactions (e.g., in vivo behavior) are largely unexplored. Therefore, it is important to engineer PEG particles with different physicochemical properties and examine their biological behavior to aid in the development of next-generation, long-circulating drug delivery systems.

Herein, we investigate the influence of the PEG molecular weight, particle size, and presence or absence of a template on phagocytic blood cell association and biodistribution of the particles (Figure 1). To facilitate efficient PEG loading in the MS templates, 8-arm-PEG with amine functional groups (8-arm-PEG- $\mathrm{NH}_{2}$ ) was used to infiltrate the MS templates exploiting electrostatic interactions. PEG particles were obtained by cross-linking the amine groups, followed by removal of the MS templates. Three different molecular weights $(10,20$, or $40 \mathrm{kDa}$ ) of 8 -arm-PEG-NH $\mathrm{N}_{2}$ were used as building blocks. The size of the PEG particles was tuned by varying the initial template diameters between 100 and $1000 \mathrm{~nm}$ (specifically 110, 280, 500 and $1000 \mathrm{~nm})$. In addition, the free amine groups could be modified with functional moieties, such as fluorescent dyes to permit visualization of the particles for in vitro and ex vivo studies, or cage amine ligands capable of coordinating positronemitting ${ }^{64} \mathrm{Cu}$ for in vivo biodistribution studies. 

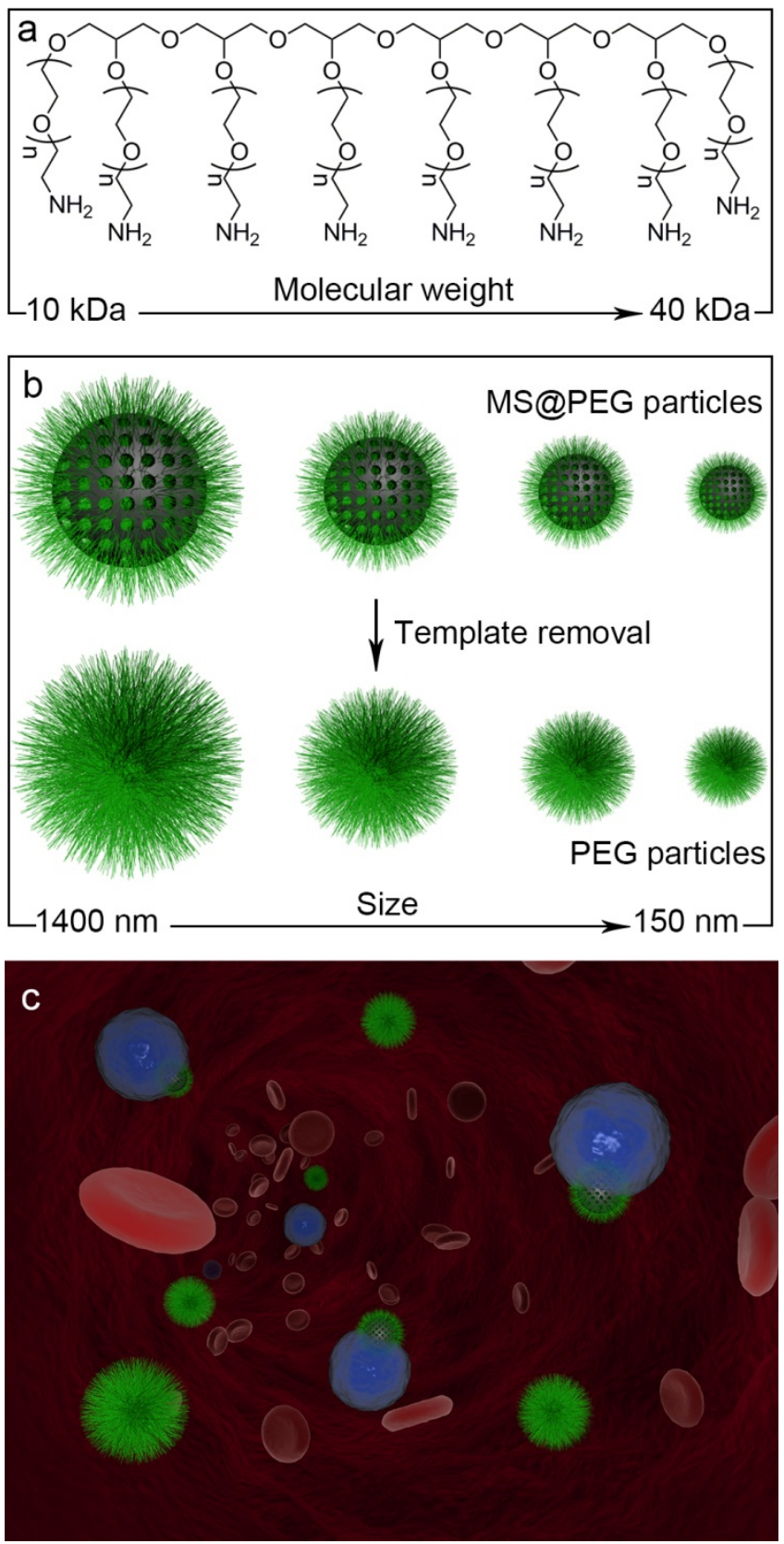

Figure 1. (a) Molecular structure of 8-arm-PEG-NH $\mathrm{N}_{2}$ for particle fabrication. (b) Schematic illustration of the MS@PEG (template present) and PEG particles (template absent) with different sizes. (c) Schematic illustration of the retention of PEG particles in the blood stream, which indicates their low phagocytic cell (blue) association and extended circulation time, compared with MS@PEG particles.

An understanding of biological interactions in vitro and in vivo is required for the design of stealthy drug carriers. In vitro experiments typically measure phagocyte association using cell 
lines to select promising candidates for in vivo studies. It is generally assumed that particles with lower cell association have extended circulation times. ${ }^{32,33}$ However, particles incubated with cell lines may behave differently to particles placed in more complex environments such as human tissue, human blood, or the circulatory system of animals. In this study, we incubated the particles with fresh, whole human blood at $37{ }^{\circ} \mathrm{C}$ to investigate phagocytic blood cell association, which predicts in vivo circulation behavior more accurately than traditional assays. We observed that increasing PEG molecular weight or decreasing particle size reduced phagocytic blood cell association of the PEG particles. MS@PEG particles resulted in higher blood cell association compared to their template-free PEG particles. Similarly, biodistribution studies in mice showed that the PEG particles had superior in vivo circulation times (>12 h) compared with the MS@PEG particles and that smaller PEG particles $(150 \mathrm{~nm})$ resulted in higher blood retention and longer circulation times.

\section{RESULTS AND DISCUSSION}

For the construction of PEG particles, four different sizes of MS particles with average diameters of 1000, 500, 280, and 110 nm (denoted as MS-1000, MS-500, MS-280, and MS110 particles, respectively) were synthesized. The three larger templates were synthesized using polyelectrolyte-surfactant complexes as dynamic templates according to a modified literature method. ${ }^{34}$ The size control of the MS particles was controlled by varying the concentration of polyelectrolytes, where less polyelectrolyte resulted in a smaller particle

diameter. ${ }^{34}$ Smaller MS particles $(110 \mathrm{~nm})$ were synthesized using cetyltrimethylammonium tosylate as the templating surfactant and small organic amines (i.e., triethanolamine) as base. $^{35}$ The spherical morphology and porous structure of the MS particles are shown in the transmission electron microscopy (TEM) images (Figure 2a1-d1). For the fabrication of the PEG particles, 8-arm-PEG- $\mathrm{NH}_{2}$ with a hexaglycerol core structure was infiltrated into the MS 
templates, driven by electrostatic interactions. ${ }^{26}$ The amine groups of the 8 -arm-PEG-NH were then partially cross-linked with 8-arm-PEG functionalized with succinimidyl carboxyl methyl ester (8-arm-PEG-NHS, Figure S1a), which resulted in MS@PEG particles. The PEG particles were obtained by dissolving the MS templates. Alexa Fluor 488 carboxylic acid, succinimidyl ester (AF488) was used to fluorescently label the PEG particles for visualization by fluorescence microscopy. Figure 2a2-d2 shows fluorescence microscopy images of the PEG particles with different sizes (denoted as PEG40-1000, PEG40-500, PEG40-280, and PEG40-110 particles, respectively), where MS-1000, MS-500, and MS-280 were used as templates, respectively, and the PEG with a molecular weight of $40 \mathrm{kDa}$ was used for particle fabrication. All of the particles were well dispersed in aqueous solution, showing homogeneous fluorescence, and swelling $\sim 40 \%$ relative to their respective templates (Table S1). Note that the fluorescence images of PEG40-110 particles were taken via immobilizing the particles in $2.5 \%$ agarose gel (low melting point) to prevent diffusion of the particles (Figure 2d2,d3). Zeta potential measurements showed that the PEG particles were $\sim 15 \mathrm{mV}$ in water, which indicates there are still free amine groups in the particles. However, the zeta potential became neutral at $\mathrm{pH} 7.4$ in $10 \mathrm{mM}$ phosphate buffer, which may be due to the hydrolysis of the N-hydroxysuccinimide (NHS) ester forming carboxylate groups during the cross-linking step and the charge screening by salt. Fourier transform infrared spectroscopy (FTIR) measurements proved the presence of carboxylate groups $\left(1730 \mathrm{~cm}^{-1}\right)$ in the PEG particles (Figure S2). However, it was difficult to discern the $\mathrm{N}-\mathrm{H}\left(3409 \mathrm{~cm}^{-1}\right)$ peak for both 8-arm-PEG-NH 2 and PEG particles. Atomic force microscopy (AFM) measurements of the PEG particles showed that the PEG particles collapsed following air-drying, and that the thickness of the particles was just $~ 1 / 100$ times the diameter of the PEG particles in aqueous solution (Figure 2a3-c3 and Table S1). This indicates that the PEG particles are highly hydrated in aqueous solution. TEM was also used to elucidate the structure of the PEG 
particles in the dry state, which shows that they dehydrate and spread on the copper grid (Figure 2a4-c4); this is consistent with the results of AFM measurements. Note that because of dehydration, the PEG40-110 nm particles could not be detected by AFM or TEM. For a comparison of the parameters governing particle formation, 8-arm-PEG- $\mathrm{NH}_{2}$ with different molecular weights $(10,20$, and $40 \mathrm{kDa}$ ) were used to assemble PEG particles (template diameter, $1000 \mathrm{~nm}$ ). These particles are denoted as PEG10-1000, PEG20-1000, and PEG401000 particles, respectively. The thickness of the PEG particles after air-drying was lower when higher molecular weight PEG was used (Figure S3), which indicates that the PEG particles prepared with higher molecular weight PEG were more hydrated in aqueous solution. Because of the neutral charge and extensive hydration, the PEG particles were expected to exhibit stealth properties in biological systems. 

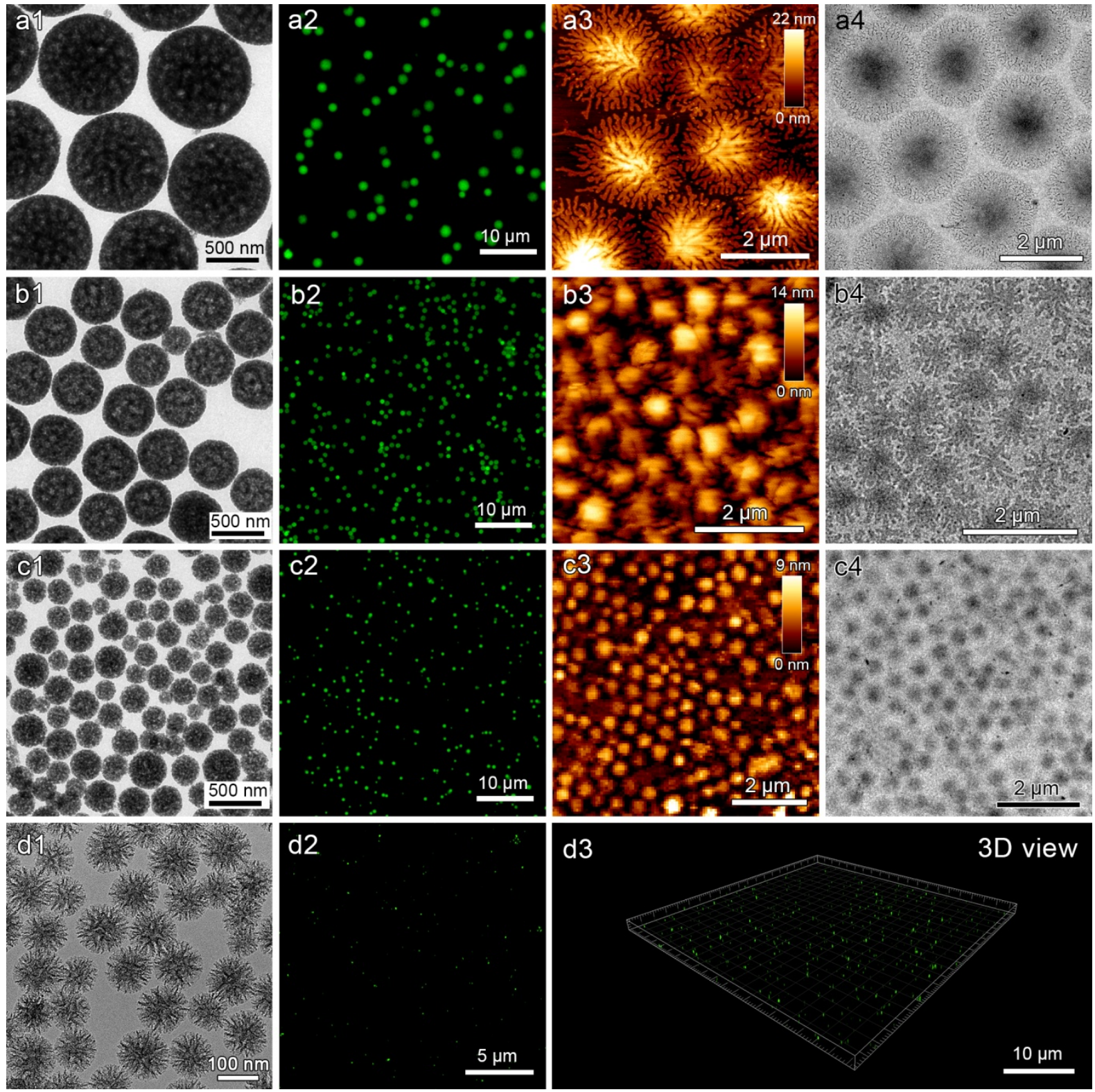

Figure 2. TEM images of the MS particles with diameters of (a1) 1000 nm, (b1) 500 nm, (c1) $280 \mathrm{~nm}$, and (d1) $110 \mathrm{~nm}$. Fluorescence microscopy images of AF488-labeled (a2) PEG401000, (b2) PEG40-500, (c2) PEG40-280, and (d2,d3) PEG40-110 particles. (a3-c3) AFM images and (a4-c4) TEM images of the (a3,a4) PEG40-1000, (b3,b4) PEG40-500, and (c3,c4) PEG40-280 particles, respectively.

To investigate the stealth properties of the PEG particles, we first assessed the cell association of the MS@PEG and PEG particles using the THP-1 cell line, which is a human monocytic cell line commonly studied in phagocytosis assays. There was less cell association 
for the PEG particles compared to the corresponding MS@PEG particles (Figure S4). Also, smaller MS@PEG40 particles resulted in less cell association, which may be due to differences in sedimentation and particle diffusion. ${ }^{36}$ For the PEG particles, THP-1 cell association was less than 3\% and the PEG particles prepared with higher molecular weight PEG (i.e., longer PEG arms) induced less cell association. This is most likely because of the increased hydration mentioned above and because longer PEG chains result in a thicker protective layer. ${ }^{16}$ The low levels of association for the PEG particles precluded detecting significant differences between the cell associations of the smaller PEG particles (i.e., PEG40-500 and PEG40-280).

Monocytes and granulocytes play a major role in the elimination of pathogens, dead or dying cells, and foreign bodies in the blood. ${ }^{37}$ This property can restrict the capacity of particles to reach target cells to deliver the payload. A human whole blood assay is therefore a more relevant model system to test the stealth properties of particles when compared to cell lines derived from one specific type of blood cell. To visualize the cell association of the PEG particles in whole blood, we labeled monocytes and granulocytes with fluorescent antibodies. After incubation with particles, cell association was observed using deconvolution microscopy (Figure S5). Cell-associated particles were almost exclusively internalized by these professional phagocytes. PEG10-1000 particles were internalized by about 30\% of monocytes and in low numbers (1-2 particles), while $~ 80 \%$ of monocytes contained MS@PEG10-1000 particles. Similar observations were made for granulocyte association, which inspired a more quantitative look at cell association in whole blood using flow cytometry.

Cell association was investigated for the PEG and MS@PEG particles with gated populations of monocytes and granulocytes using flow cytometry after incubating the 
particles in whole human blood for 1, 5 or $21 \mathrm{~h}$ (Figure S6). In agreement with the results observed from the THP-1 cell association experiments, higher molecular weight PEG resulted in less cell association for PEG particles (Figure 3a). We found that the monocyte association was higher than the granulocyte association for the same particles $(p<0.001)$, although the effect of PEG molecular weight on particle association was the same for both cell populations. Compared with the PEG particles, the cell association of the MS@PEG particles was significantly higher (all above 50\% after $1 \mathrm{~h}$ incubation, $p<0.001$ ). Increasing the incubation time to $5 \mathrm{~h}$ induced higher cell association for the PEG particles, although cell association remained low for PEG40-1000 particles. In comparison, almost all of the cells associated with the MS@PEG particles, regardless of the PEG molecular weight after $5 \mathrm{~h}$ incubation. Overall, there was much higher particle association with human blood phagocytes compared with the THP-1 cell line, which demonstrates that this is a more sensitive assay to detect reductions in phagocyte association for different particle compositions. 

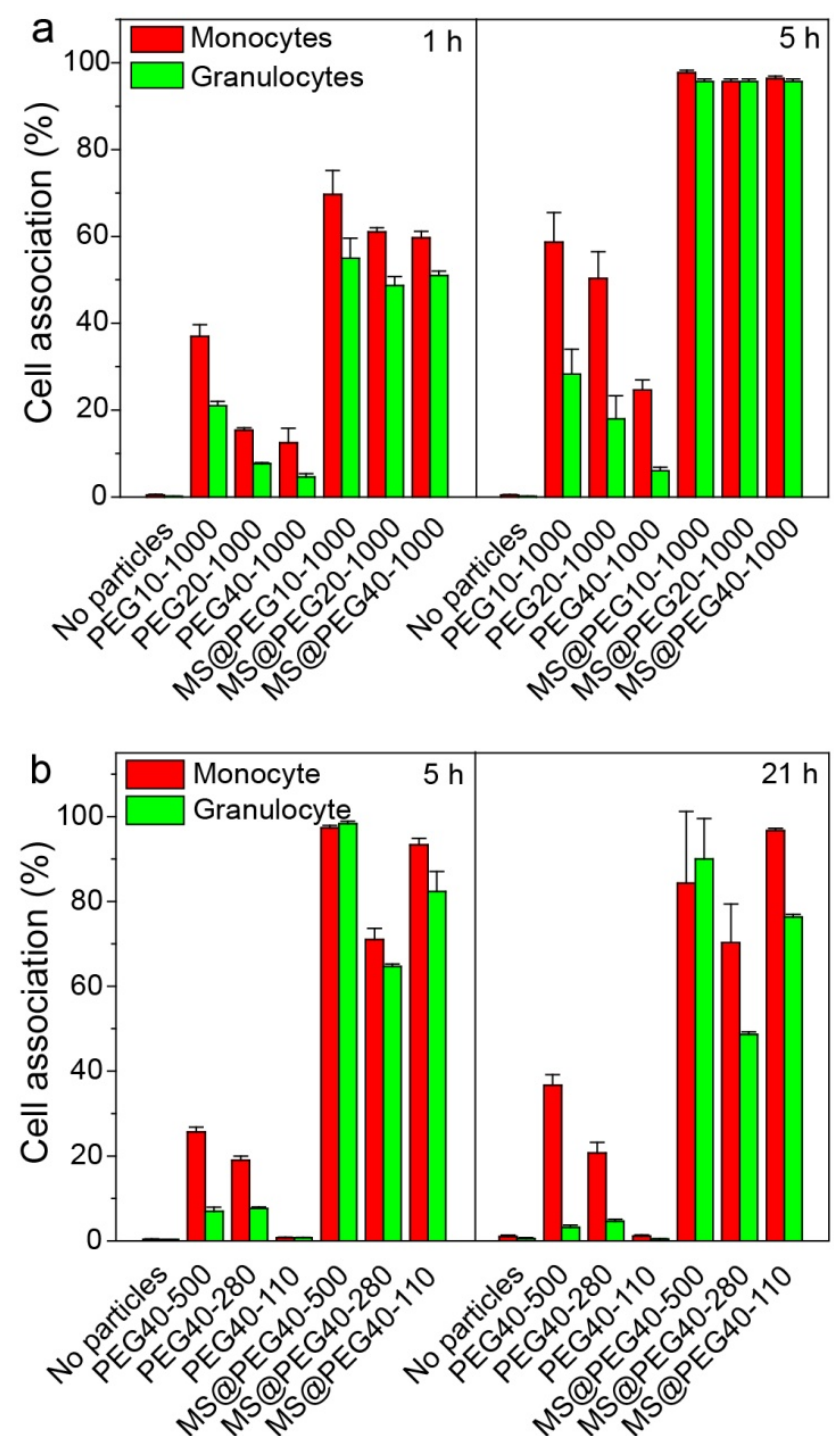

Figure 3. Association (\% of cells) of PEG and MS@PEG particles with monocytes and granulocytes after 1,5 or $21 \mathrm{~h}$ incubation at $37{ }^{\circ} \mathrm{C}$ in whole blood, measured by flow cytometry. (a) Influence of PEG molecular weight on cell association (template diameter, $1000 \mathrm{~nm}$ ). (b) Influence of particle size on cell association (PEG molecular weight, $40 \mathrm{kDa}$ ).

On the basis of the results obtained above, we focused our study on the $40 \mathrm{kDa}$ PEG, since higher molecular weight PEG resulted in less cell association for the PEG particles. To investigate the influence of the particle size on the cell association, PEG40 and MS@PEG40 with different sizes were incubated with human blood for 5 or 21 h. From Figure 3b, smaller PEG particles resulted in less cell association, a result that could not be concluded with 
confidence from the THP-1 cell association assay. For all sizes, the association for MS@PEG particles was much higher than that for the PEG particles $(p<0.001)$. Except for the sedimentation effect, ${ }^{36}$ this may be also because of the differences in elasticity of the obtained particles due to template removal, ${ }^{38,39}$ where MS@PEG particles with silica cores are almost incompressible, while PEG particles cross-linked with $2 \mathrm{mg} \mathrm{mL}^{-1}$ of cross-linker have a low Young's modulus of $\sim 1.6 \mathrm{kPa}^{26}$ Non-PEG polymer particles (thiolated poly(methacrylic acid), PMA $_{\mathrm{SH}}, 10 \%$ modification),${ }^{40}$ were used as a control to check cell association. The different sizes of PMA $\mathrm{SH}_{\mathrm{SH}}$ had higher cell association in whole blood than similarly sized PEG particles (Figure S7), confirming the importance of PEG for the stealth property of the particles rather than the soft-polymeric nature of the particles. Despite increased monocyte association for PEG40-500 and PEG40-280 particles after $21 \mathrm{~h}$ incubation compared to $5 \mathrm{~h}$ incubation, association of PEG40-110 particles remained below 1\%, making them good candidates to examine their circulation in vivo. 

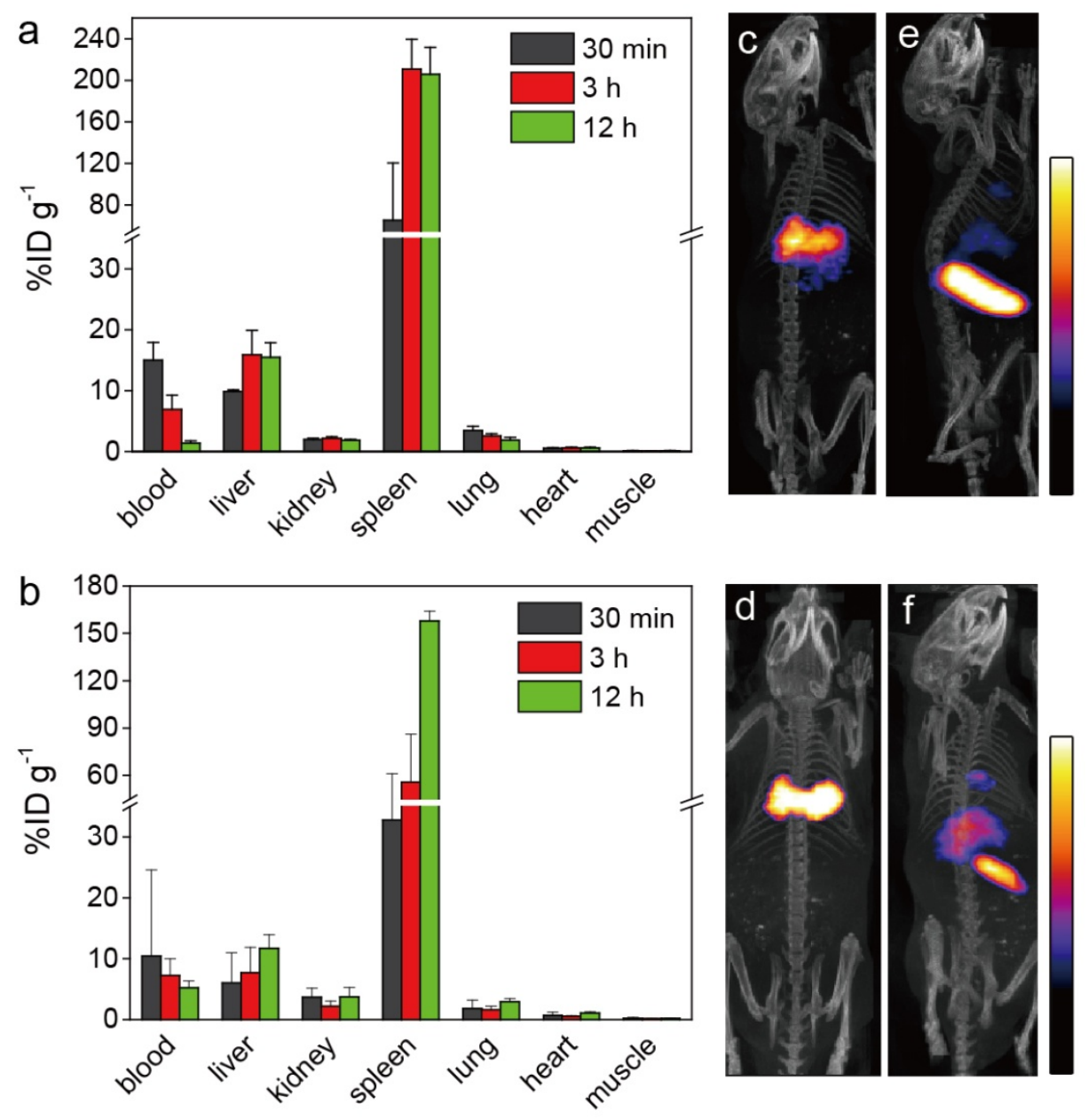

Figure 4. Biodistribution of ${ }^{64} \mathrm{Cu}$-labeled (a) PEG40-500 and (b) PEG40-280 particles in various organs at three different time points (30 min, $3 \mathrm{~h}$, and $12 \mathrm{~h}$ ) after intravenous injection. Data are presented as percentage injected dose per gram (\%ID g $\left.{ }^{-1}\right)$ of tissue. All data represent three mice per group. (c-f) PET/CT images of mice 30 min post-injection of (c) MS@PEG40-500, (d) MS@PEG40-280, (e) PEG40-500, and (f) PEG40-280 particles. The color scale for all PET/CT image data shows radiotracer uptake with white corresponding to the highest activity and blue to the lowest activity.

For in vivo studies, a macrobicyclic cage amine ligand was first conjugated to the particles by the reaction of amine groups and macrobicyclic cage amine ligand (1- $\mathrm{CH}_{3}-8$ $\mathrm{NHCO}\left(\mathrm{CH}_{2}\right)_{3} \mathrm{CO}_{2}$-NHS) sarcophagine (MeCOSar-NHS) (Figure S1b). Cage amine ligands of the sarcophagine (sar, 3,6,10,13,16,19-hexaaza-bicyclo[6.6.6]icosane) type form extremely 
stable and kinetically inert $\mathrm{Cu}^{\mathrm{II}}$ complexes. ${ }^{41-43}$ The MS@PEG40 and PEG40 particles were further labeled with ${ }^{64} \mathrm{Cu}$ via incubation with ${ }^{64} \mathrm{Cu}$ solution in $\mathrm{PBS}$ at $\mathrm{pH} 7.2$ for $30 \mathrm{~min}$ at room temperature. The particles were washed twice with PBS and resuspended in PBS buffer. Less than $0.1 \%$ of the initial ${ }^{64} \mathrm{Cu}$ amount was found in the second wash fraction, indicating efficient clean up. To examine the in vivo biodistribution of the particles, $5 \times 10^{8}$ radiolabeled particles were intravenously injected into each healthy C57BL/6 mouse. The animals were sacrificed at different time points after intravenous injection, and the blood and organs were removed to measure the radioactivity level using a gamma-counter. Distribution of PEG40-500 and PEG40-280 particles from blood to tissues occurred mostly in the first $30 \mathrm{~min}$ and the blood accumulation of these particles decreased to $10-15 \% \mathrm{ID} \mathrm{g}^{-1}$ (Figure 4a,b). Subsequently, 50\% of the PEG40-500 particles were eliminated after $3 \mathrm{~h}$ and there was only $1.4 \% \mathrm{ID} \mathrm{g}^{-1}$ left in the blood. However, it took about $12 \mathrm{~h}$ to eliminate $50 \%$ of the PEG40-280 particles, which indicates that the PEG40-280 particles circulate longer than the PEG40-500 particles. In comparison, the MS@PEG40-500 and MS@PEG40-280 particles were completely cleared from the blood less than 30 min after injection (data not shown), indicating that the PEG40 particles had extended in vivo circulation times compared with the MS@PEG particles. As shown in Figure 4a and 4b, except for retention in the blood, PEG particles mostly accumulated in the spleen and liver, since they are the mononuclear phagocytic systems (MPS) for clearing foreign blood-borne particulate entities. ${ }^{44,45}$ Positron emission tomography-computed tomography (PET/CT) imaging confirmed the biodistribution results, which revealed prominent uptake of MS@PEG40 particles and PEG40 particles in the liver and spleen 30 min post-injection, respectively (Figure 4c-f). In addition, some PEG particles in the heart were observed (Figure 4e,f), which is attributed to the heart containing a certain amount of blood at any given time and because there is some retention of PEG40 particles in the blood. 

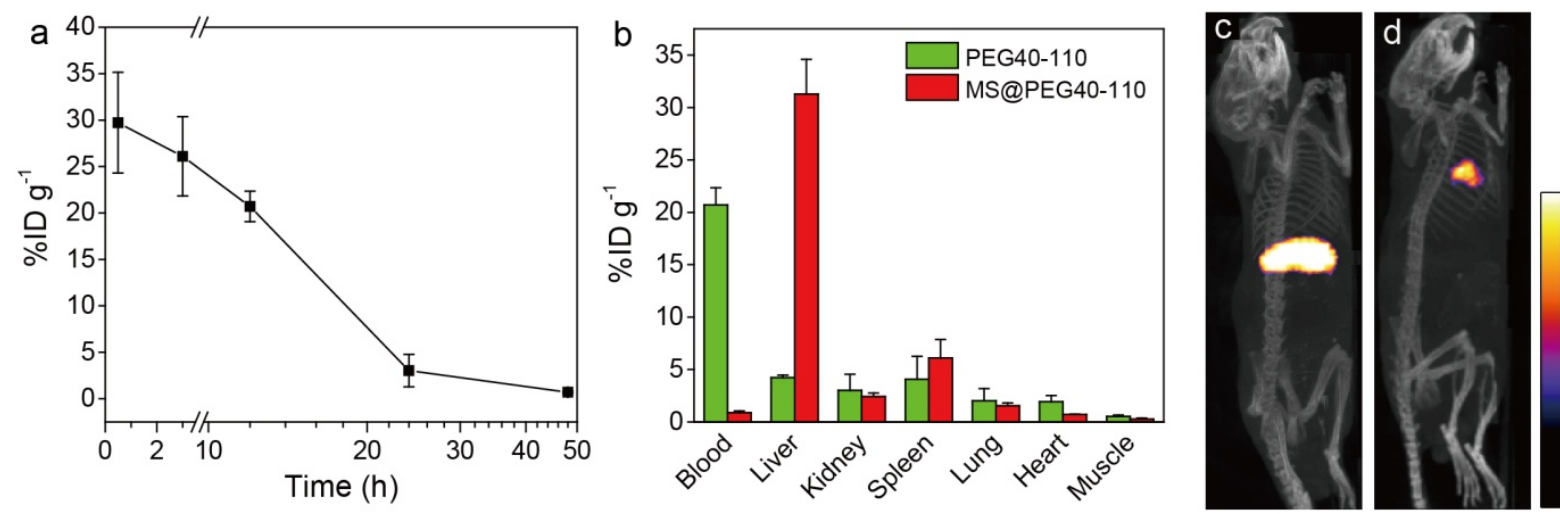

Figure 5. (a) Blood radioactivity of the ${ }^{64} \mathrm{Cu}$-labeled PEG40-110 at different time points. (b) Biodistribution of ${ }^{64} \mathrm{Cu}$-labeled MS@PEG40-110 and PEG40-110 particles in various organs at $12 \mathrm{~h}$ after intravenous injection. PET/CT images of mice $12 \mathrm{~h}$ post-injection of (c) MS@PEG40-110 and (d) PEG40-110 particles. The color scale for all PET/CT image data shows radiotracer uptake with white corresponding to the highest activity and blue to the lowest activity. All data represent three mice per group.

Since the PEG40-280 particles have higher blood retention than the PEG40-500 particles $12 \mathrm{~h}$ post-injection, decreasing the size of PEG particles was expected to result in a higher circulation time. To this end, the retention of PEG40-110 particles in the blood was three times higher 30 min post-injection and four times higher $12 \mathrm{~h}$ post-injection compared to the PEG40-280 particles (Figure 5a); this is a promising circulation profile for future drug delivery applications. Similar to PEG40-280 particles, PEG40-110 particles were eliminated slowly from blood over the next $12 \mathrm{~h}$ post-injection. In addition, it took about $14.5 \mathrm{~h}$ to eliminate the initial $30 \% \mathrm{ID} \mathrm{g}^{-1}$ detected 30 min post-injection. As shown in Figure 5b, most of the PEG40-110 particles remained in systemic circulation $12 \mathrm{~h}$ post-injection and there was low biodistribution in the MPS such as the liver and spleen. On the contrary, MS@PEG40-110 particles mainly accumulated in the liver. PET/CT imaging also revealed the high presence of the MS@PEG40-110 particles in the liver and a large number of the 
PEG40-110 particles in the heart were observed due to their high retention in the blood. From the biodistribution results, it can be concluded that the MS@PEG particles are eliminated quickly $(<30 \mathrm{~min}$ ) regardless of size and that the smaller PEG particles result in higher blood retention and longer circulation time, which is consistent with the prediction from the ex vivo blood cell association experiments.

\section{CONCLUSIONS}

We have demonstrated the fabrication of PEG hydrogel particles using MS particles with different diameters $(1000,500,280$, and $110 \mathrm{~nm})$ as templates, and 8-arm-PEG-NH $\mathrm{NH}_{2}$ with different molecular weights $(10,20$, and $40 \mathrm{kDa})$ as building blocks that were modified with functional groups (e.g., dyes or cage amine ligands capable of coordinating positronemitting ${ }^{64} \mathrm{Cu}$ ). Using a sensitive and relevant ex vivo assay of fresh human blood, we found that the PEG particles prepared with higher molecular weight PEG and smaller diameter templates resulted in lower levels of cell association with phagocytic blood cells. The MS@PEG particles showed higher phagocytic blood cell association compared with the PEG particles. In vivo experiments were consistent with the ex vivo experiments, and the PEG particles had improved biodistribution when compared to MS@PEG particles. The PEG40110 particles showed extended in vivo circulation times $(>12 \mathrm{~h})$, with blood retention increased by at least four times $12 \mathrm{~h}$ post-injection compared to larger PEG particles. The reported templating technique for fabricating diverse PEG particles represents a new platform to investigate parameters that determine biological interactions in vitro and in vivo. Further studies will focus on the capability of the PEG particles to carry and deliver therapeutic payloads.

\section{METHODS}


Materials. Tetraethyl orthosilicate (TEOS), poly(acrylic acid) (PAA, Mw 250 kDa, 35 wt\% solution in water), cetyltrimethylammonium bromide (CTAB), cetyltrimethylammonium tosylate (CTAT), triethanolamine, sodium phosphate dibasic, $\mathrm{N}$-(3dimethylaminopropyl)- $N$ '-ethylcarbodiimide hydrochloride (EDC), hydrofluoric acid (HF, 48 wt\%), ammonium fluoride $\left(\mathrm{NH}_{4} \mathrm{~F}\right)$, and ammonium hydroxide solution (28-30\%) were obtained from Sigma-Aldrich (Australia). 8-arm-PEG-NH 2 (10, 20, and $40 \mathrm{kDa}$ ) and 8-armPEG-NHS (10 kDa) with a hexaglycerol core structure were purchased from JenKem Technology USA Inc. (China) and Creative PEGWorks (USA), respectively. Poly(methacrylic acid, sodium salt) (PMA, $\mathrm{M}_{\mathrm{w}} 15 \mathrm{kDa}, 30 \mathrm{wt} \%$ solution in water) was from Polysciences, Inc. (USA). Pyridine dithioethylamine (PDA) was purchased from Shanghai SpeedChemical Co. Ltd. (China). Alexa Fluor 488 carboxylic acid, succinimidyl ester (AF488), heat inactivated fetal bovine serum (HI-FBS), and RPMI 1640 Medium with GlutaMAX ${ }^{\mathrm{TM}}$ Supplement (RPMI) was provided by Invitrogen (Australia). ${ }^{64} \mathrm{CuCl}_{2}$ solution (0.02 M HCl, no carrier added) was produced at Sir Charles Gairdner Hospital (Nedlands, Western Australia) through the ${ }^{64} \mathrm{Ni}(\mathrm{p}, \mathrm{n}){ }^{64} \mathrm{Cu}$ nuclear reaction. The water used in all experiments was prepared in a three-stage Millipore Milli-Q Plus 185 purification system and had a resistivity greater than $18.2 \mathrm{M} \Omega \mathrm{cm}$.

Synthesis of MS Particles. For the synthesis of MS-1000 particles, $1.1 \mathrm{~g}$ of CTAB was completely dissolved in $50 \mathrm{~mL}$ of water with stirring. Subsequently, $4.3 \mathrm{~g}$ of PAA solution was added with vigorous stirring at room temperature $\left(25^{\circ} \mathrm{C}\right)$ until a clear solution was obtained. Next, $3.5 \mathrm{~mL}$ of ammonium hydroxide solution was added to the above solution with vigorous stirring, resulting in a milky suspension. After stirring for $20 \mathrm{~min}, 4.46 \mathrm{~mL}$ of TEOS was added to the above solution. Following further stirring for $15 \mathrm{~min}$, the mixture was transferred into a Teflon-sealed autoclave, which was left at $100{ }^{\circ} \mathrm{C}$ for $48 \mathrm{~h}$. The assynthesized MS particles were washed with water and ethanol three times, and finally dried at 
$80{ }^{\circ} \mathrm{C}$. The organic templates were removed by calcination at $550{ }^{\circ} \mathrm{C}$ for $6 \mathrm{~h}$. Size control of 500 and $280 \mathrm{~nm}$ was achieved by varying the concentration of the PAA. For the synthesis of the MS-110 particles, $480 \mathrm{mg}$ of CTAT and $347 \mathrm{mg}$ of triethanolamine were dissolved in 25 $\mathrm{mL}$ of water at $80^{\circ} \mathrm{C}$. Then $3.9 \mathrm{~mL}$ of TEOS was quickly added into the surfactant solution. The mixture was vigorously stirred at $80{ }^{\circ} \mathrm{C}$ for another $2 \mathrm{~h}$. The synthesized MS particles were washed with water and ethanol, dried at $80^{\circ} \mathrm{C}$, and finally calcined at $550{ }^{\circ} \mathrm{C}$ for $6 \mathrm{~h}$.

Synthesis of (t-Boc) ${ }_{4-5}$ MeCOSar-NHS-ester. To a solution of (t-Boc) ${ }_{4-5} \mathrm{MeCOSar}(0.05$ g, $0.055 \mathrm{mmol}$ ), consisting of a mixture of N-tert-butoxycarbonyl (t-Boc) regioisomers in dry DMF (1 mL), was added 1-ethyl-3-(3-dimethylaminopropyl)carbodiimide (0.02 g, 0.11 mmol) followed by N-hydroxysuccinimide $(0.01 \mathrm{~g}, 0.11 \mathrm{mmol})$. The solution was stirred under a nitrogen atmosphere at $60{ }^{\circ} \mathrm{C}$ for $3.5 \mathrm{~h}$. The reaction was monitored by ESIMS. The solvent was removed in vacuo and the residue was extracted with dichloromethane $(100 \mathrm{~mL})$ and washed with water $(100 \mathrm{~mL})$ three times. The organic phase was dried over anhydrous $\mathrm{MgSO}_{4}$, filtered and evaporated to dryness and purified by flash chromatography on a silica gel (mobile phase: dichloromethane/methanol $=100 / 2(\mathrm{v} / \mathrm{v})$ ) to give a mixture of $\mathrm{t}$-Boc regioisomers as a white solid (0.023 g, 46\% approx. yield based on four t-Boc groups). ${ }^{1} \mathrm{H}$ NMR (400 MHz, $\left.\mathrm{CDCl}_{3}, 25{ }^{\circ} \mathrm{C}\right): \delta=1.47, \mathrm{~s},\left(\mathrm{CH}_{3}\right)_{3} ; 2.81, \mathrm{~s}, 4 \mathrm{H}, \mathrm{CH}_{2}(\mathrm{NHS}) .{ }^{13} \mathrm{C} \mathrm{NMR}$ (100 MHz, $\mathrm{CDCl}_{3}, 25^{\circ} \mathrm{C}$ ): $\delta=20.6 . \mathrm{CH}_{3} ; 25.7, \mathrm{CH}_{2} ; 28.6,\left(\mathrm{CH}_{3}\right)_{3}, \mathrm{CH}_{2} ; 30.4, \mathrm{CH}_{2}$. Further NMR assignments proved difficult due to the mixture of regioisomers. ESI-MS: (+ve ion) $\left[\mathrm{C}_{44} \mathrm{H}_{77} \mathrm{~N}_{8} \mathrm{O}_{13}+\mathrm{H}^{+}\right]$m/z 100\% 925.56 (experimental), 925.56 (calcd), $\left[\mathrm{C}_{49} \mathrm{H}_{85} \mathrm{~N}_{8} \mathrm{O}_{15}+\mathrm{H}^{+}\right.$] m/z 100\% 1025.61 (experimental), 1025.61 (calcd).

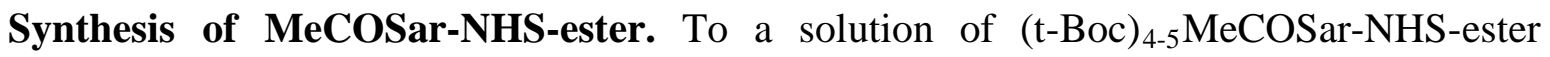
(0.023 g, $0.025 \mathrm{mmol})$ in dichloromethane $(5 \mathrm{~mL})$ was added trifluoroacetic acid $(5 \mathrm{~mL})$. The mixture was shaken at room temperature for $3 \mathrm{~h}$. The solution was purged with $\mathrm{N}_{2}$ to reduce 
the volume to $1 \mathrm{~mL}$. Cold diethyl ether ( $45 \mathrm{~mL}$ ) was added to precipitate a white solid. Following centrifugation ( $3 \mathrm{~min}, 1000 \mathrm{~g}$ ) the ether layer was removed by decanting and the procedure was repeated. Finally, the majority of the residual diethyl ether was removed in vacuo and the tris-trifluoroacetic acid tris-hydrate salt of the compound was isolated $(0.017 \mathrm{~g}$, 71\% approx. yield based on four t-Boc groups). (Found: C, 39.58; H, 5.65; N, 11.84; calcd for $\mathrm{C}_{24} \mathrm{H}_{44} \mathrm{~N}_{8} \mathrm{O}_{5} \cdot 3\left(\mathrm{C}_{2} \mathrm{HF}_{3} \mathrm{O}_{2}\right) \cdot 3\left(\mathrm{H}_{2} \mathrm{O}\right) \cdot 0.2\left(\mathrm{C}_{4} \mathrm{H}_{10} \mathrm{O}\right)$ : C, 39.54; $\left.\mathrm{H}, 5.93 ; \mathrm{N}, 11.98\right) .{ }^{1} \mathrm{H}$ NMR (500 MHz, $\mathrm{d}_{6}$-dmso, $25^{\circ} \mathrm{C}$ ): $\delta=0.86, \mathrm{~s}, 3 \mathrm{H}, \mathrm{CH}_{3} ; 1.09, \mathrm{t}, \mathrm{CH}_{3}\left(\mathrm{Et}_{2} \mathrm{O}\right) ; 1.84, \mathrm{~m}, 2 \mathrm{H}, \mathrm{CH}_{2}$; 2.27, t, ${ }^{3} \mathrm{~J}=7.5 \mathrm{~Hz}, 2 \mathrm{H}, \mathrm{CH}_{2} ; 2.72, \mathrm{t},{ }^{3} \mathrm{~J}=7.5 \mathrm{~Hz}, 2 \mathrm{H}, \mathrm{CH}_{2} ; 2.82$, s, 4H, $\mathrm{CH}_{2}$ (NHS); 2.9-3.2, br m, 24H, cage $\mathrm{CH}_{2} \cdot{ }^{13} \mathrm{C}$ NMR (125.7 MHz, $\mathrm{d}_{6}$-dmso, $\left.25^{\circ} \mathrm{C}\right): \delta=15.2, \mathrm{CH}_{3}\left(\mathrm{Et}_{2} \mathrm{O}\right) ; 19.7$, $\mathrm{CH}_{3} ; 20.0, \mathrm{CH}_{2} ; 25.4, \mathrm{CH}_{2}$ (NHS); 29.5, 34.0, $\mathrm{CH}_{2}$; 36.7, quat. C of methyl cage cap; 45.8, 47.2, 50.6, 53.2, cage $\mathrm{CH}_{2}$; 56.5, quat. C of amine cage cap; 64.9, $\mathrm{CH}_{2}\left(\mathrm{Et}_{2} \mathrm{O}\right) ; 117.0$, q, ${ }^{1} \mathrm{~J}_{\mathrm{CF}}$ $=299 \mathrm{~Hz}, \mathrm{CF}_{3} ; 158.3, \mathrm{q},{ }^{2} \mathrm{~J}_{\mathrm{CF}}=31 \mathrm{~Hz}, \mathrm{COCF}_{3} ; 168.8, \mathrm{CO} ; 170.2$, CO (NHS); 173.6, CO. ESI-MS: (+ve ion) $\left[\mathrm{C}_{24} \mathrm{H}_{44} \mathrm{~N}_{8} \mathrm{O}_{5}+\mathrm{H}^{+}\right] \mathrm{m} / \mathrm{z} 100 \% 525.35$ (experimental), 525.35 (calcd).

Fabrication of MS@PEG and PEG Particles. Approximately 6 mg of MS particles was washed with phosphate buffer (100 mM, pH 8) and incubated in $480 \mu \mathrm{L}$ of 8 -arm-PEG-NH${ }_{2}$ solution (5 mg mL ${ }^{-1}$ in phosphate buffer) with constant shaking overnight. Subsequently, the particles were isolated by centrifugation and washed three times with phosphate buffer. The pellet was dispersed in $400 \mu \mathrm{L}$ of 8 -arm-PEG-NHS solution ( $2 \mathrm{mg} \mathrm{mL}^{-1}$ in phosphate buffer) and incubated for $2 \mathrm{~h}$, where PEG was cross-linked and formed networks in the MS particles. The MS@PEG particles were labeled with AF488 (5 $\mu \mathrm{L}, 1 \mathrm{mg} \mathrm{mL}^{-1}$ ) or MeCOsar-NHS (5 $\mu \mathrm{L}, 1 \mathrm{mg} \mathrm{mL} \mathrm{m}^{-1}$ ) during the cross-linking step. After three washing cycles with water, the MS@PEG particles were resuspended in water. For the preparation of PEG particles, MS templates were removed with a $2 \mathrm{M} \mathrm{HF} / 8 \mathrm{M} \mathrm{NH}_{4} \mathrm{~F}$ solution $(\mathrm{pH} \sim 5) .{ }^{46}$ Caution! HF is highly toxic. Extreme care should be taken when handling HF solution and only small quantities should be prepared. The resultant PEG particles were washed three times with water and 
resuspended in water. The MeCOsar-NHS-modified PEG particles were dispersed in $20 \mathrm{mM}$ phosphate buffer ( $\mathrm{pH} 7.4$ ) for further ${ }^{64} \mathrm{Cu}$ labeling.

Fabrication of PMA $\mathbf{A H}_{\mathrm{SH}}$ Particles. PMA $\mathrm{PDA}_{\mathrm{A}}$ was synthesized via EDC-mediated amide bond formation between the carboxyl groups of PMA and the amine groups of PDA. ${ }^{28}$ In a typical experiment, a PMA solution (360 mg of $30 \mathrm{wt} \%$ solution, 1 equiv. of MA) was diluted into $5 \mathrm{~mL}$ of phosphate buffer (0.1 M, pH 7.2). The resulting solution was incubated with EDC (57.5 mg, 0.3 equiv.) with stirring for $15 \mathrm{~min}$. Subsequently, PDA (33.4 mg, 0.15 equiv.) was added to the mixture and the $\mathrm{pH}$ was adjusted to 7.2. The reaction was allowed to proceed overnight. The resulting mixture was placed inside a dialysis membrane (molecular weight cut-off 3500, Thermo) and dialyzed extensively against water, filtered with a $0.2 \mu \mathrm{m}$ syringe filter, and isolated via lyophilization. The degree of thiol functionalization was characterized by measuring the absorbance of the released pyridine-2-thione $\left(\lambda_{\max }=343 \mathrm{~nm}\right)$, and then quantified from a calibration curve of PDA, which corresponded to $10 \mathrm{~mol} \%$ modification. $\mathrm{PMA}_{\mathrm{SH}}$ particles were fabricated via thiol-disulfide exchange cross-linking according to our previously published method. ${ }^{39}$ The concentration of the cross-linker $\left(\mathrm{PMA}_{\mathrm{SH}}\right)$ was $0.5 \mathrm{mg} \mathrm{mL}^{-1}$.

THP-1 Cell Association. THP-1 cells (ATCC) were seeded in a 24-well plate (70 000 cells per well) in RPMI media with the addition of $10 \%(\mathrm{v} / \mathrm{v})$ HI-FBS and incubated with AF488labeled MS@PEG or PEG particles at a particle-to-cell ratio of 100:1 for 24 h at $37{ }^{\circ} \mathrm{C}$ in a $5 \% \mathrm{CO}_{2}$ humidified atmosphere. After incubation, the cells were collected and washed with PBS three times via centrifugation at $400 \mathrm{~g}$ for $5 \mathrm{~min}$. The resulting cell pellets were resuspended in PBS and analyzed by flow cytometry (Apogee Micro Flow Cytometer).

Blood Cell Association and Imaging. Whole blood from healthy volunteers was collected into Sodium Heparin Vacuette tubes (Greiner Bio-One). A single source of blood was used 
for flow cytometry and an alternate single source of blood for microscopy. Particles were incubated with $100 \mu \mathrm{L}$ of blood at $37^{\circ} \mathrm{C}$ and $5 \% \mathrm{CO}_{2}$ for 1 or $5 \mathrm{~h}$ in $5 \mathrm{~mL}$ polystyrene tubes (BD Biosciences, San Jose, CA). The particle:leukocyte ratio was 100:1 for all experiments.

For flow cytometry, prior to particle incubation, leukocytes in whole blood were phenotyped at $37^{\circ} \mathrm{C}$ for 30 min with CD45-V500 (BD, clone HI30), CD3-Alexa Fluor 700 (BD, clone SP34-2), CD14-APC H7 (BD, clone M $\varphi$ P9), CD20-Brilliant violet 421 (BioLegend, Clone 2H7), CD56-PE (BD, Clone B159) and HLA-DR-PerCP Cy5.5 (BD, Clone G46-6). Particle incubation was terminated by washing in 10 volumes of BD FACS Lysing Solution (BD) followed by a wash with $4 \mathrm{~mL}$ of PBS. Cells were fixed with BD stabilizing fixative and acquired within a few hours on a LSRFortessa (BD). Analysis was performed using FlowJo software, version 9.6.4. Leukocytes (CD45+) were distinguished from contaminating erythrocytes (CD45-). Monocytes were identified as CD14+ and granulocytes as CD14-/SSC ${ }^{\text {hi }}$.

For imaging, particles were incubated with blood as above for $1 \mathrm{~h}$. Particle incubation was terminated and red blood cells were lysed by adding 10 volumes of BD Pharm Lyse Lysing Buffer (BD) followed by a wash with $4 \mathrm{~mL}$ of PBS. Monocytes and granulocytes were purified by cell sorting using a MoFlo Astrios. Purified monocytes were then stained with CD14-APC (BD, Clone M5E2) and purified granulocytes with CD66c-PE (BD, clone B6.2) for microscopy. Cells and associated particles were visualized using a DeltaVision deconvolution microscope.

Human Research and Ethics Committee approval was obtained for all studies of human samples and informed signed consent was obtained from the subjects.

PET Studies and Post-Mortem Biodistribution. Healthy mice were injected with ${ }^{64} \mathrm{Cu}-$ labeled particles via a lateral tail vein. After $20 \mathrm{~min}$ or $12 \mathrm{~h}$ incubation, a PET scan was 
performed using a NanoPET/CT In Vivo Preclinical Imager (Bioscan, Washington DC, USA) with a 10 min PET acquisition time, and coincidence relation of 1-3. Image reconstruction was performed with the following parameters: OSEM with SSRB 2D LOR, energy window, 400-600 keV; filter Ramlak cut off 1, number of iteration/subsets, 8/6. For the CT scans, an X-ray voltage of $45 \mathrm{kVp}$, an exposure time of $900 \mathrm{~ms}$ and a pitch of 0.5 were used. A total projection of 240 projects over $360^{\circ}$ of rotation was acquired. Projection data was rebinned by 1:4 and reconstructed using a RamLak filter into a matrix having an isotropic voxel size of $96 \mu \mathrm{m}$. Image files of PET and CT scans were fused and analyzed using the analysis software InVivoScope version 2.00 .

For particle biodistribution studies, the mice ( $\mathrm{n}=3$ each group) were injected with ${ }^{64} \mathrm{Cu}$ labeled particles via a lateral tail vein and sacrificed at different time points (30 min, $3 \mathrm{~h}, 12$ h, 24 h or 48 h). The mice were perfused with PBS, the organs and blood were removed and measured with an aliquot of injected solution as standard in the gamma counter (Perkin Elmer) using an energy window between 450 and $650 \mathrm{keV}$. Results are expressed as \% injected dose per gram $\left(\% \mathrm{ID} \mathrm{g}^{-1}\right)$ of tissue.

All experiments involving animals were approved by the Alfred Medical Research and Education Precinct Animal Ethics Committee (E/1232/2012/B).

Characterization Methods. TEM analysis was carried out with a Philips CM120 BioTWIN instrument operated at $120 \mathrm{kV}$. AFM images were acquired with a NanoWizard II AFM (JPK Instruments, Berlin, Germany). Aqueous particle suspensions were air-dried onto silicon wafers, which were pre-cleaned with Piranha solution. Caution! Piranha solution is extremely corrosive and reacts violently with organic materials. It should be handled with great care. Fluorescence microscopy images were taken using an Olympus IX71 inverted fluorescence microscope equipped with a DIC slider (U-DICT, Olympus), the corresponding 
filter sets, and a 60× oil immersion objective (Olympus UPFL20/0.5NA, W.D. 1.6). The degree of PDA functionalization was quantified via absorbance readings at $343 \mathrm{~nm}$ using a NanoDrop 1000 spectrophotometer (Thermo Scientific, Australia). FTIR experiments were conducted on a Varian 7000 spectrometer. Zeta potential measurements of the particles were conducted with a Malvern Zetasizer Nano ZS. Particle counting and the THP-1 cell association assay were performed on an Apogee Micro Flow Cytometer at an excitation wavelength of $488 \mathrm{~nm}$. Deconvolution fluorescence microscopy was performed on a DeltaVision (Applied Precision) microscope with a $60 \times 1.42$ NA oil objective with a standard FITC/TRITC/CY5 filter set. High-resolution fluorescence images of PEG40-110 particles were taken via a DeltaVision OMX microscope (Applied Precision). Images were processed with Imaris (Bitplane) using the maximum intensity projection. LSRFortessa (BD) was used for all blood cell association assays.

Supporting Information. Molecular structure of 8-arm-PEG-NHS and MeCOsar-NHS, size, zeta potential and THP-1 cell association of PEG and MS@PEG particles, AFM images of PEG particles prepared with different molecular weight PEG, deconvolution microscopy images of monocytes and granulocytes after incubation with PEG10-1000 or MS@PEG101000 particles, gating strategy for monocyte and granulocyte association of PEG particles, monocyte and granulocyte association of the PMA $\mathrm{PH}_{\mathrm{SH}}$ particles. This material is available free of charge via the Internet at http://pubs.acs.org.

\section{AUTHOR INFORMATION}

\section{Corresponding Authors}

skent@unimelb.edu.au, fcaruso@unimelb.edu.au

\section{Author Contributions}

${ }^{\perp}$ J. Cui and R. De Rose contributed equally. 


\section{ACKNOWLEDGMENT}

This work was supported by the Australian Research Council under the Australian Laureate Fellowship (F.C., 120100030), Discovery Project (F.C., 130101846), Super Science Fellowship (F.C., FS110200025), Discovery Early Career Researcher Award (Y.Y., DE130100488), Future Fellowship (K.P., FT0992210), and by the National Health and Medical Research Council (NHMRC) program (S.J.K., 510448), project (K.P. and C.E.H., 1029249) and fellowship awards (S.J.K., 508937). R.D. is supported by the NHMRC Career Development Fellowship (APP1011578), K.A. is supported by the German Research Foundation (Al 1521/1-1) and C.E.H. is supported by a National Heart Foundation Career Development Fellowship (CR 11M 6066). The work was also supported in part by the Victorian Government's Operational Infrastructure Support Program, Monash Biomedical Imaging and Victoria's Science Agenda Strategic Project Fund. We also acknowledge Clarity Pharmaceuticals for supply and delivery of the ${ }^{64} \mathrm{Cu}$, and Benjamin Hibbs (The University of Melbourne) for help in acquiring the high-resolution fluorescence images. 
Table of Contents

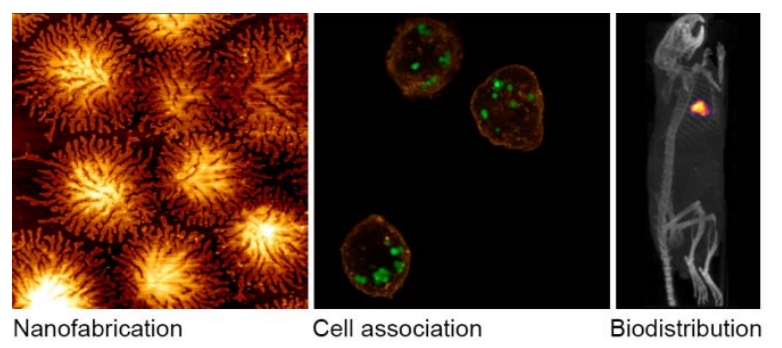




\section{REFERENCES}

1. Farokhzad, O. C.; Langer, R. Impact of Nanotechnology on Drug Delivery. ACS Nano 2009, 3, 16-20.

2. Petros, R. A.; DeSimone, J. M. Strategies in the Design of Nanoparticles for Therapeutic Applications. Nat. Rev. Drug Discovery 2010, 9, 615-627.

3. Shi, J.; Votruba, A. R.; Farokhzad, O. C.; Langer, R. Nanotechnology in Drug Delivery and Tissue Engineering: From Discovery to Applications. Nano Lett. 2010, 10, 3223-3230.

4. Devadasu, V. R.; Bhardwaj, V.; Kumar, M. N. Can Controversial Nanotechnology Promise Drug Delivery? Chem. Rev. 2013, 113, 1686-1735.

5. $\quad$ Ariga, K.; Kawakami, K.; Ebara, M.; Kotsuchibashi, Y.; Ji, Q.; Hill, J. P. Bioinspired Nanoarchitectonics as Emerging Drug Delivery Systems. New J. Chem. 2014, 38, 5149-5163.

6. Elsabahy, M.; Wooley, K. L. Design of Polymeric Nanoparticles for Biomedical Delivery Applications. Chem. Soc. Rev. 2012, 41, 2545-2561.

7. Cui, J.; van Koeverden, M. P.; Müllner, M.; Kempe, K.; Caruso, F. Emerging Methods for the Fabrication of Polymer Capsules. Adv. Colloid Interface Sci. 2014, 207, 1431.

8. Yan, Y.; Björnmalm, M.; Caruso, F. Assembly of Layer-by-Layer Particles and Their Interactions with Biological Systems. Chem. Mater. 2014, 26, 452-460.

9. Albanese, A.; Tang, P. S.; Chan, W. C. The Effect of Nanoparticle Size, Shape, and Surface Chemistry on Biological Systems. Annu. Rev. Biomed. Eng. 2012, 14, 1-16.

10. Kolhar, P.; Anselmo, A. C.; Gupta, V.; Pant, K.; Prabhakarpandian, B.; Ruoslahti, E.; Mitragotri, S. Using Shape Effects to Target Antibody-Coated Nanoparticles to Lung and Brain Endothelium. Proc. Natl. Acad. Sci. U.S.A. 2013, 110, 10753-10758.

11. Barua, S.; Yoo, J.-W.; Kolhar, P.; Wakankar, A.; Gokarn, Y. R.; Mitragotri, S. Particle Shape Enhances Specificity of Antibody-Displaying Nanoparticles. Proc. Natl. Acad. Sci. U.S.A. 2013, 110, 3270-3275.

12. Howard, M. D.; Jay, M.; Dziubla, T. D.; Lu, X. PEGylation of Nanocarrier Drug Delivery Systems: State of the Art. J. Biomed. Nanotechnol. 2008, 4, 133-148.

13. Wattendorf, U.; Merkle, H. P. PEGylation as a Tool for the Biomedical Engineering of Surface Modified Microparticles. J. Pharm. Sci. 2008, 97, 4655-4669.

14. Chertok, B.; Webber, M. J.; Succi, M. D.; Langer, R. Drug Delivery Interfaces in the 21st Century: From Science Fiction Ideas to Viable Technologies. Mol. Pharm. 2013, 10, 3531-3543.

15. Perry, J. L.; Reuter, K. G.; Kai, M. P.; Herlihy, K. P.; Jones, S. W.; Luft, J. C.; Napier, M.; Bear, J. E.; DeSimone, J. M. PEGylated Print Nanoparticles: The Impact of PEG Density on Protein Binding, Macrophage Association, Biodistribution, and Pharmacokinetics. Nano Lett. 2012, 12, 5304-5310.

16. Perrault, S. D.; Walkey, C.; Jennings, T.; Fischer, H. C.; Chan, W. C. Mediating Tumor Targeting Efficiency of Nanoparticles through Design. Nano Lett. 2009, 9, 19091915.

17. Nance, E. A.; Woodworth, G. F.; Sailor, K. A.; Shih, T.-Y.; Xu, Q.; Swaminathan, G.; Xiang, D.; Eberhart, C.; Hanes, J. A Dense Poly(Ethylene Glycol) Coating Improves Penetration of Large Polymeric Nanoparticles within Brain Tissue. Sci. Transl. Med. 2012, 4, 149 ra119.

18. Yang, Q.; Jones, S. W.; Parker, C. L.; Zamboni, W. C.; Bear, J. E.; Lai, S. K. Evading Immune Cell Uptake and Clearance Requires PEG Grafting at Densities Substantially Exceeding the Minimum for Brush Conformation. Mol. Pharm. 2014, 11, 1250-1258. 
19. Rolland, J. P.; Maynor, B. W.; Euliss, L. E.; Exner, A. E.; Denison, G. M.; DeSimone, J. M. Direct Fabrication and Harvesting of Monodisperse, Shape-Specific Nanobiomaterials. J. Am. Chem. Soc. 2005, 127, 10096-10100.

20. Xu, J.; Wong, D. H. C.; Byrne, J. D.; Chen, K.; Bowerman, C.; DeSimone, J. M. Future of the Particle Replication in Nonwetting Templates (PRINT) Technology. Angew. Chem. Int. Ed. 2013, 52, 6580-6589.

21. Dendukuri, D.; Pregibon, D. C.; Collins, J.; Hatton, T. A.; Doyle, P. S. ContinuousFlow Lithography for High-Throughput Microparticle Synthesis. Nat. Mater. 2006, 5, 365369.

22. Pregibon, D. C.; Toner, M.; Doyle, P. S. Multifunctional Encoded Particles for HighThroughput Biomolecule Analysis. Science 2007, 315, 1393-1396.

23. Haghgooie, R.; Toner, M.; Doyle, P. S. Squishy Non-Spherical Hydrogel Microparticles. Macromol. Rapid Commun. 2010, 31, 128-134.

24. Yap, H. P.; Johnston, A. P. R.; Such, G. K.; Yan, Y.; Caruso, F. Click-Engineered, Bioresponsive, Drug-Loaded PEG Spheres. Adv. Mater. 2009, 21, 4348-4352.

25. Müllner, M.; Cui, J.; Noi, K. F.; Gunawan, S. T.; Caruso, F. Surface-Initiated Polymerization within Mesoporous Silica Spheres for the Modular Design of Charge-Neutral Polymer Particles. Langmuir 2014, 30, 6286-6293.

26. Cui, J.; Björnmalm, M.; Liang, K.; Xu, C.; Best, J. P.; Zhang, X.; Caruso, F. SuperSoft Hydrogel Particles with Tunable Elasticity in a Microfluidic Blood Capillary Model. Adv. Mater. 2014, 26, 7295-7299.

27. Wang, Y.; Yan, Y.; Cui, J.; Hosta-Rigau, L.; Heath, J. K.; Nice, E. C.; Caruso, F. Encapsulation of Water-Insoluble Drugs in Polymer Capsules Prepared Using Mesoporous Silica Templates for Intracellular Drug Delivery. Adv. Mater. 2010, 22, 4293-4297.

28. Cui, J.; Yan, Y.; Wang, Y.; Caruso, F. Templated Assembly of pH-Labile PolymerDrug Particles for Intracellular Drug Delivery. Adv. Funct. Mater. 2012, 22, 4718-4723.

29. Cui, J.; De Rose, R.; Best, J. P.; Johnston, A. P. R.; Alcantara, S.; Liang, K.; Such, G. K.; Kent, S. J.; Caruso, F. Mechanically Tunable, Self-Adjuvanting Nanoengineered Polypeptide Particles. Adv. Mater. 2013, 25, 3468-3472.

30. Mertz, D.; Tan, P.; Wang, Y.; Goh, T. K.; Blencowe, A.; Caruso, F. Bromoisobutyramide as an Intermolecular Surface Binder for the Preparation of FreeStanding Biopolymer Assemblies. Adv. Mater. 2011, 23, 5668-5673.

31. Cui, J.; Wang, Y.; Hao, J.; Caruso, F. Mesoporous Silica-Templated Assembly of Luminescent Polyester Particles. Chem. Mater. 2009, 21, 4310-4315.

32. Walkey, C. D.; Olsen, J. B.; Guo, H.; Emili, A.; Chan, W. C. Nanoparticle Size and Surface Chemistry Determine Serum Protein Adsorption and Macrophage Uptake. J. Am. Chem. Soc. 2012, 134, 2139-2147.

33. Sheng, Y.; Yuan, Y.; Liu, C.; Tao, X.; Shan, X.; Xu, F. In Vitro Macrophage Uptake and In Vivo Biodistribution of PLA-PEG Nanoparticles Loaded with Hemoglobin as Blood Substitutes: Effect of PEG Content. J. Mater. Sci.: Mater. Med. 2009, 20, 1881-1891.

34. Wang, J.-G.; Zhou, H.-J.; Sun, P.-C.; Ding, D.-T.; Chen, T.-H. Hollow Carved SingleCrystal Mesoporous Silica Templated by Mesomorphous Polyelectrolyte-Surfactant Complexes. Chem. Mater. 2010, 22, 3829-3831.

35. Zhang, K.; Xu, L. L.; Jiang, J. G.; Calin, N.; Lam, K. F.; Zhang, S. J.; Wu, H. H.; Wu, G. D.; Albela, B.; Bonneviot, L. et al. Facile Large-Scale Synthesis of Monodisperse Mesoporous Silica Nanospheres with Tunable Pore Structure. J. Am. Chem. Soc. 2013, 135, 2427-2430.

36. Cho, E. C.; Zhang, Q.; Xia, Y. The Effect of Sedimentation and Diffusion on Cellular Uptake of Gold Nanoparticles. Nat. Nanotechnol. 2011, 6, 385-391. 
37. Dale, D. C.; Boxer, L.; Liles, W. C. The Phagocytes: Neutrophils and Monocytes. Blood 2008, 112, 935-945.

38. Banquy, X.; Suarez, F.; Argaw, A.; Rabanel, J.-M.; Grutter, P.; Bouchard, J.-F.; Hildgen, P.; Giasson, S. Effect of Mechanical Properties of Hydrogel Nanoparticles on Macrophage Cell Uptake. Soft Matter 2009, 5, 3984-3991.

39. Zhang, L.; Cao, Z.; Li, Y.; Ella-Menye, J.-R.; Bai, T.; Jiang, S. Softer Zwitterionic Nanogels for Longer Circulation and Lower Splenic Accumulation. ACS Nano 2012, 6, 66816686.

40. Best, J. P.; Cui, J.; Müllner, M.; Caruso, F. Tuning the Mechanical Properties of Nanoporous Hydrogel Particles via Polymer Cross-Linking. Langmuir 2013, 29, 9824-9831.

41. Sargeson, A. M. The Potential for the Cage Complexes in Biology. Coord. Chem. Rev. 1996, 151, 89-114.

42. Di Bartolo, N. M.; Sargeson, A. M.; Donlevy, T. M.; Smith, S. V. Synthesis of a New Cage Ligand, Sarar, and Its Complexation with Selected Transition Metal Ions for Potential Use in Radioimaging. J. Chem. Soc., Dalton Trans. 2001, 2303-2309.

43. Alt, K.; Paterson, B. M.; Ardipradja, K.; Schieber, C.; Buncic, G.; Lim, B.; Poniger, S. S.; Jakoby, B.; Wang, X.; O’Keefe, G. J. et al. Single-Chain Antibody Conjugated to a Cage Amine Chelator and Labeled with Positron-Emitting Copper-64 for Diagnostic Imaging of Activated Platelets. Mol. Pharm. 2014, 11, 2855-2863.

44. Zhang, G.; Yang, Z.; Lu, W.; Zhang, R.; Huang, Q.; Tian, M.; Li, L.; Liang, D.; Li, C. Influence of Anchoring Ligands and Particle Size on the Colloidal Stability and In Vivo Biodistribution of Polyethylene Glycol-Coated Gold Nanoparticles in Tumor-Xenografted Mice. Biomaterials 2009, 30, 1928-1936.

45. Zhao, Y.; Sultan, D.; Detering, L.; Cho, S.; Sun, G.; Pierce, R.; Wooley, K. L.; Liu, Y. Copper-64-Alloyed Gold Nanoparticles for Cancer Imaging: Improved Radiolabel Stability and Diagnostic Accuracy. Angew. Chem. Int. Ed. 2014, 53, 156-159.

46. Shimizu, K.; Cha, J.; Stucky, G. D.; Morse, D. E. Silicatein $\alpha$ : Cathepsin L-Like Protein in Sponge Biosilica. Proc. Natl. Acad. Sci. U.S.A. 1998, 95, 6234-6238. 


\section{University Library}

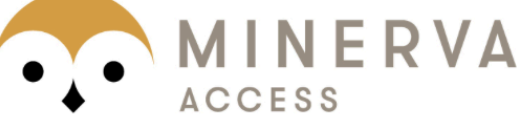

A gateway to Melbourne's research publications

Minerva Access is the Institutional Repository of The University of Melbourne

Author/s:

Cui, J;De Rose, R;Alt, K;Alcantara, S;Paterson, BM;Liang, K;Hu, M;Richardson, JJ;Yan, Y;Jeffery, CM;Price, RI;Peter, K;Hagemeyer, CE;Donnelly, PS;Kent, SJ;Caruso, F

Title:

Engineering Poly(ethylene glycol) Particles for Improved Biodistribution

Date:

2015-02-01

Citation:

Cui, J., De Rose, R., Alt, K., Alcantara, S., Paterson, B. M., Liang, K., Hu, M., Richardson, J. J., Yan, Y., Jeffery, C. M., Price, R. I., Peter, K., Hagemeyer, C. E., Donnelly, P. S., Kent, S. J. \& Caruso, F. (2015). Engineering Poly(ethylene glycol) Particles for Improved Biodistribution. ACS NANO, 9 (2), pp.1571-1580. https://doi.org/10.1021/nn5061578.

Persistent Link:

http://hdl.handle.net/11343/90866 